\title{
An Actor-Network Perspective on Collections Documentation and Data Practices at Museums
}

\author{
Juhee Park
}

\begin{abstract}
The improvement of digital technology over recent decades has advanced the ability of museums to manage records of their collections and share them online. However, despite the rise of research in the area of digital heritage, less attention has been given to a sociotechnical perspective on such technology. Drawing upon concepts from Actor-Network Theory, this paper presents actors associated with the V\&A's collections management system and its online catalogue. Digital design objects, the museum's new type of collection, are seen as a driving force for change in collections documentation practices. This paper argues for models of documentation to change from closed to open and participatory in order to (re) present such objects' materiality in collection records through the voices of multiple actors. This paper, highlighting the agency of data and technology, increases our awareness of the potential consequences of museums' data practices where the integration of advanced technology (e.g., $\mathrm{Al}$ ) will be implemented in the future.
\end{abstract}

Key words: Actor-Network Theory, collections management systems, online catalogues, materiality of digital objects, agency of data

\section{Introduction: Museums and Sociotechnical Systems}

The emergence and evolution of computing technology has drawn museums' attention towards leveraging such technology for collections documentation and management since the 1960s (Jones 2008). The standardization of their catalogue metadata and the development of semantic systems have been pushed forward continuously by international museum communities, not only to improve the internal efficiency of collections management at museums but also the interoperability of collections data among cultural institutions (Baca 2008). ${ }^{1}$ Internet technology has made museums' collection records accessible to the general public via online catalogues.

In recent decades, as a reflection of the increase in such applications of computing technology in museum practices, studies on museums' collections management systems (CMSs) and websites have diversified. For example, researchers have studied CMSs data modelling and data standards to improve such systems' performance (see, for example, Bearman 2008; Oldman et al. 2016) while others have explored the structure of museum websites and online users' behaviours, expectations, and goals to increase our understanding of digital audiences (see, for example, Marty 2008). ${ }^{2}$ However, those studies mostly see CMSs and museum websites as coherent, stable technological objects. In other words, they start with an assumption that such systems are taken for granted. Less attention has been given to CMSs and museum websites from a sociotechnical perspective (Akrich 1992) which considers the social dimension of technology in use and understands such objects within a social context. A few exceptions are Cameron's studies (2008; 2020), which provide new conceptual insights on museum collections data within a digital space where hybrid actors (e.g., human and non-human) are connected, and Wilson's paper (2011), which highlights the role of internet technology and program languages that construct the experiences of online audiences on museum websites.

Building upon the development of a sociotechnical perspective on computing technology and digital systems adopted in museums, this paper takes a critical approach to museums' 
CMSs and online catalogues. By drawing on concepts from Actor-Network Theory (ANT), which allows one to explore a technological object, such as software, as a network of actors (Latour 2005), this paper aims to unpack the network of human and non-human actors contributing to the construction of how CMSs and online catalogues currently work. In other words, this theoretical element of the paper attempts to understand the interplay between the technological systems and the social, organizational contexts (e.g., museums) that are in use. It investigates not only the museum conventions and protocols that are relevant to collections' documentation practices but also the standardized metadata of collection object records and textual searching-based interfaces of online catalogues that affect how the interaction between collections and online users (e.g., the public) are shaped. This paper will demonstrate how CMSs are punctualized (Callon 1991) with hybrid actors, how metadata of collection records controls its network as a spokesperson (Callon 1986), and why online catalogues are still a closed network where missing actors (e.g., the public) are still not recognized.

This paper builds on the primary outputs of the research project 'Content/Data/Object'3 within the V\&A Research Institute (VARI) (see Park 2019). ${ }^{4}$ The project addresses theoretical and practical issues that the museum faces when collecting, documenting, and displaying digital design objects, for instance, personal digital devices, software, mobile applications, and video games. This paper will show how the new type of collections become a driving force not only for making previously invisible sociotechnical systems and their hybrid actors visible and recognizable but also for establishing a change in museum conventions for collections documentation and from closed models of CMSs to open and participatory ones.

\section{Actor-Network Theory as a Lens to Uncover Relationships between Museums and Digital Systems}

Studying a CMS and an online catalogue in a museum context is, in a broad sense, an attempt to understand the relationship between an organization and a technological system that is exclusively adopted by the organization. To establish an appropriate theoretical foundation for the research, we must consider Actor-Network Theory (ANT), which treats the social and the technical as inseparable. This section introduces the key concepts of ANT that will help build my argument that current models of CMSs (as a result of punctualization) and metadata of collection records (as a spokesperson) only represent selective actors of museums' digital design objects. I will then explain research methods.

\section{Agency of non-human actors}

Actor-Network Theory rejects the dualistic framework that separates humans and things. Instead, the theory allows researchers to address each entity as having equal agency (Law 1992; Latour 2005). Agency within ANT terminology is a minimal conception of agency that is 'decoupled from criteria of intentionality, subjectivity, and free will' (Sayes 2014: 141). What this means is that non-human actors have agency in the same manner as human actors do. They can be acknowledged within the existence of 'many metaphysical shades between full causality and sheer in-existence: things might authorize, allow, afford, encourage, permit, suggest, influence, block, render possible, forbid, and so on' (Latour 2004: 226). Sayes further explains this concept by quoting Latour, a leading proponent of ANT, 'Latour (2005: 71) maintains that one need only ask of an entity: "[d]oes it make a difference in the course of some other agent's action or not? Is there some trial that allows someone to detect this difference?" If we can answer yes to these two questions, then we have an actor that is exercising agency - whether this actor is non-human or otherwise' (Sayes 2014: 141).

The acknowledgement of the agency of non-human actors (software, for example) has brought about new insight into the study of information systems within organizations (see Walsham 1997; Doolin and Lowe 2002; Hanseth et al. 2004). Walsham (1997: 467) advocates an ANT approach that allows one to investigate hybrids of people and information technology, as

$[T]$ he symbolic boundary between people and information technology is in a constant state of flux across a wide spectrum of contemporary work and leisure activities, and Actor-Network Theory offers one way to investigate the issues and dilemmas in this new world. 
In other words, ANT can help facilitate a better understanding of the interaction between the social (e.g., organizations) and the technical system (e.g., CMSs) in the social context of the development, implementation, and use of such a system, rather than the de facto treatment of technology as simple tools used by humans. Research surrounding museum studies (Cameron 2008; Kéfi and Pallud 2011 and Waller 2016, for instance) also attempts, from an ANT perspective, to bring about new understandings on the complex interplay between museums, museum practitioners, museum collections and digital technology. This paper considers museums' CMS, online catalogue, metadata of collection records, and digital design objects as sociotechnical objects (Akrich 1992), which are not just final products but also fluid actors with agency (Latour 2005) that negotiate with other actors who might have different goals.

\section{Stabilization of actor-networks: spokesperson and punctualization}

The agency of actors and actor-networks are not fixed (Law 1992; Latour 2005). They are temporary and fragile and subject to change, given that actors are in continuous negotiation with each other. Through the negotiation process of translation (Callon 1986), some actors could become more influential on the grounds of their strong associations with other actors while others could become less recognizable and hidden. If an actor can make it possible to render other networked actors mobile, the actor becomes a spokesperson of its association who can now represent others' opinions (Callon 1986). A spokesperson does not have to be a human actor. Even non-human actors such as metadata can be spokespeople, as I will argue throughout this paper.

An actor is, in fact, a relational effect (Latour 2005), which can be unfolded endlessly in theory. The success of any actor-network makes us misconceptualize it as a coherent, independent, stable actor rather than a hybrid network (Callon 1991). For example, a laptop appears to be a solitary product. When interacting with a laptop, we do not notice all the actors it networks with: a screen, a keyboard, standards of keyboard, electricity, internet, internet protocols, an operating system, microchips, the laptop's manufacturing company, factory workers, conceptions of digital divides and cybersecurity, to name a few. We simply switch on the laptop to send an email without noticing these details. The laptop here is punctualized (Callon 1991). According to Callon (1991: 153), 'the process of punctualization ... converts an entire network into a single point or node in another network'. The simplified network consisting of hybrid actors becomes durable over time and space until there is an attempt to unfold its complexities.

Law (1992) identifies strategies that make for a more stable network. For example, a network embodying more durable material may last longer than others. Written texts and physical buildings may be more durable than invisible speech and thoughts. When considering space, if a network has the possibility to control its entities at a distance, from central to marginal, then it may become stronger. If there is a repeated pattern that can be found and anticipated in the future, the process of network building can then become more effective.

Based on these concepts, this paper will see CMSs punctualized. It will illustrate how metadata of collection records becomes a spokesperson that permits or hinders what values of collections are to be documented. Standardized metadata of museums' collection records that have strong connections with museums' collections documentation policies and guidelines will be understood as a strategy that exclusively enhances associated actors' agency and renders their network visible and durable.

\section{Actor-Network Theory and the materiality of museums' digital design objects}

The temporality of actors' agencies, particularly in relation to non-human actors, can be read in conjunction with the notion of the affordances of objects (Gibson 1986) and the relational character of the affordances when articulating the materiality of digital objects (Leonardi 2010). Leonardi (2010) notes that 'Although the physical matter of an artifact is common to each person who encounters it, the affordances of that artifact are not. Affordances are unique to the particular ways in which an actor perceives materiality'. In other words, affordances of objects that are useful for some could go unrecognized by others. This interpretation brings an interesting perspective to the study of objects in a museum context. What is meaningful to 
collect and document is relational and subjective and, therefore, ontologically plural depending on which affordances of each object are perceived by whom. This is 'because matter can provide multiple affordances, it is possible that one artifact can produce multiple outcomes' (Leonardi 2010). Digital design objects - iPhones, for example, which are mass-produced and used across the world, can ontologically mean different things to different people. This does not just refer to the physical, tangible definition of an object but also the relation of the object's value to its users. Personalized experience and interaction become crucial for the meaning-making process around such objects. ${ }^{5}$ This perspective leads us to consider the social dimensions of digital design objects' materiality 6 in a museum context when collecting and documenting these objects.

The underlying understanding of what constitutes 'materiality' has been a matter of substantial debate within a wide range of academic fields, particularly due to the broader constructivist turn (Sterne 2014). Pentland and Singh (2012: 294) argue that

materiality is not about artifacts, people, ideas, or anything ... it is about all of them, but they only become material when they influence a particular course of actions or events that we value. Materiality is all about actions, values, and consequences in context.

This further expands our understanding of materiality, departing from the physicality of objects and the intentions of human actors to the interaction between all of these actors and objects. This is where human and non-human actors interconnect with one another. Kallinikos et al. (2012: 17) also point out that, when studying materiality, an 'analysis of interaction should be central to an analysis of materiality'. It can be read with Drucker's identification of digital objects' performative materiality, as she argues that 'what something is has to be understood in terms of what it does, how it works within machinic, systemic, and cultural domains' (Drucker 2013: para 4). In other words, the materiality of digital objects lies in their performativity when they are in use through interaction with users in context.

Actor-Network Theory can be a useful tool in exploring this expanded understanding of materiality because it provides a foundation for the identification of hybrid actors of objects and analysis of interactions between them. This paper investigates what interaction occurs between the V\&A's digital design objects, the museum curators, its CMS, its online catalogue, and users of the online catalogue (e.g., the public). This analysis will help elucidate how closed models of CMS and online catalogues of museums hinder our ability to document the materiality of digital objects and to reveal silent actors (e.g., the public) hidden in the interaction.

\section{Actor-Network Theory as methodology}

A methodological approach of ANT allows researchers to analyze every actor with the same terms, whether humans or things, macro or micro (Law 1992; Latour 2005), rather than to see society within predetermined power structures. Therefore, instead of starting from an assumption of the relationship between museums and certain actors, their connections and how they affect each other will be understood through the ways this occurs from a bottomup approach. Some studies applying ANT (Waller 2016, for example) take an ethnographic approach to account for a nuanced context where researchers are situated and to provide details of what is observed. The key intention of this paper, however, presents a theoretical insight from an ANT perspective on the relation of CMSs with museums, rather than a case study, although the context of the $V \& A$ is taken as a starting point to raise questions and concerns.

To make non-human actors (e.g., CMSs, metadata, digital design objects, online catalogues) speak, I let the CMS guide me through the V\&A with the 'shadowing' (Bruni 2005) method and confront me with other actors. Relevant documents and texts (for instance, the V\&A's policy documents, the museum's blog posts, and the UK museum sector's collections documentation guidelines) alongside personal communications with museum curators were analyzed to find the footprints of non-human actors' interaction with others. The following sections respectively depunctualize the museum's CMS, digital design objects, and online catalogue and explain how digital design objects challenge the current hybrid actor-networks of CMS. 


\section{Depunctualization of the Collections Management System (CMS)}

The software that the V\&A uses for a CMS is called CollectionsIndex+, developed by System Simulation. ${ }^{7}$ It is based on NoSQL and Information Retrieval (IR) principles and is SPECTRUM compliant. ${ }^{8}$ SPECTRUM is the UK collection management standard with guidance on museum procedures. It has been developed and updated by Collections Trust (formally the Museum Documentation Association), through consultations with the museum community, since its first publication in $1994 .{ }^{9}$ The object name field in the CMS is, in principle, controlled in accordance with the Getty Art \& Architecture Thesaurus (AAT). Presumably, this is because the V\&A is an art and design museum where the terminology of AAT is believed to be suitable to categorize most of its collections. According to the museum's Collections Information and Access Policy, to 'conform appropriate national and international standards wherever possible', ${ }^{10}$ is one of the museum's principles on collections documentation. When museum curators use the CMS in daily work, they perhaps do not perceive those hybrid actors as networked. They simply consider the software a coherent technical object. Yet, the CMS is a sociotechnical, hybrid actor-network object associated with the museum community, museum objects, Collections Trust, data standards, database, software developers, and so on. Until we notice its silent networked actors, the CMS is in the state of being punctualized.

The CMSs that museums use are a reflection of the conventions of the museum sector as they are designed for internal use only at museums. Haigh (2009: 7) notes that '[S] oftware tools encapsulate craft knowledge, working practices, and cultural assumptions... these encapsulated qualities are reproduced with each new software revision, often enduring for decades'. The way the standardized metadata and controlled vocabularies of CMSs have evolved is a reflection of museum communities over the decades. Regardless of what software museums choose for their CMS, their software is expected to be compliant with standards such as SPECTRUM in the UK. Software like CMSs is 'the unseen co-author and co-interpreter of digital documentary sources' (Allen-Robertson 2018: 1743). Through the strong association with the museum sector's documentation standards, CMSs inform museum curators what to record and document about their collections.

Manovich (2013) even argues that 'software takes command', which describes how inanimate non-human actors consistently affect human activities and decision-making processes in contemporary society. Of particular significance is how culture is encoded into software and its consequences. Writing on the historical reviews of museum computing, Parry (2007: 56) maintains that 'The database, in other words, has become a rationalizing system for the modern world - more than just a tool, but a system of thought'. CMSs will not record that which it will not allow. Museum curators are expected to get along with their museum's CMS by framing their knowledge in a way that is suitable and applicable for their CMS. This is not a supportive statement for technological determinism but illustrates the agency of software.

How we understand and encounter our history and culture is fundamentally shaped not only by collecting and displaying collections but also by the ways we catalogue, classify, and document them (Srinivasan et al. 2009; Turner 2017). The way knowledge is organized through collections, collection records, collections databases, and online catalogues is significant. Museum objects displayed without adequate documentation and records could potentially cause misunderstandings about our culture and history. The following section will illustrate how challenging it is to document museums' digital design objects and their materiality on CMSs, which are solely developed with the physicality of objects in mind, in addition to museum conventions.

\section{Digital Objects at the Museum: The Outliers Disordering the Network of CMS}

The V\&A offers an 'Object Cataloguing on CMS' course that includes hands-on activities for its staff members. Museum practitioners trained in how to use the CMS are expected to follow the rules inscribed within the system. The software system received less interest as a research area until the museum's new type of collection (e.g., digital design objects) began to raise issues on collections documentation. It was at this time that the research project 'Content/Data/Object' within the museum's Research Institute began. 
Collecting digital design objects (like personal digital devices and software, for instance) is one of the areas where the Design, Architecture and Digital Department (DAD) at the V\&A is held responsible. Existing within the context of an art and design museum, DAD's collections prioritize the desire 'to consider design within the context of society, to document important global shifts in the practices and processes of design and show connections between the designed world and current socio-political concerns'.11 In other words, DAD understands digital designs as sociotechnical objects that are associated with human actors. Notably, the department even considers documenting their collection to reflect 'multiple voices and viewpoints (of gender, age, race, class, sexuality, and ability)'.12 This point has continuously received attention throughout the research project 'Content/Data/Object'.13

However, according to curators at the museum, the main issue is that the current data structure and standardized metadata of the CMS hinder them from appropriately documenting their digital design objects on the software. For instance, although physical acquisition files of such objects are full of resources that provide evidence for documenting multiple narratives around the objects, the closed model of CMS with static metadata does not provide adequate digital space, as will be further described with an example below. The underlying machinery within technology and technological systems only becomes visible when something does not work. This is known as an infrastructural inversion; it is in the breakdown of the system that true interconnectedness becomes visible (Star 1992). Digital design objects at the museum are the outlier disordering the network of CMS.

Metadata is defined literally as 'data about data' (Baca 2008). More usefully, the term is understood to mean structured data about resources. The fact that the data are structured broken down into very specific pieces - enables a range of automated and machine-readable processes to be built around the data to provide services. The profound mobility of metadata is designated by systems.

The initial intended purpose and the value of metadata in the cultural heritage sectors were to facilitate the consistency and interoperability of sharing object records throughout systems and infrastructures, as well as references for conservation (Wentz 1995; Baca 2008; Skinner 2014). At the same time, standardizing metadata and building and sharing vocabulary and terminology related to museum objects are strategies for solely making their associated actors' agency far more durable. Actors selectively empowered by CMSs become representative of the collections. In other words, metadata becomes a spokesperson of the objects while other actors (and their stories and knowledge) that do not fit the standards are excluded without the hope of being discovered in the future. For instance, Turner's (2015) study on the catalogues at the Smithsonian National Museum of Natural History shows that perspectives of indigenous communities on museum collections are not reflected in the collection records due to the conventional procedure of collections documentation and the terminology used and metadata authorized.

The agency of metadata that solely represents certain actors and neglects others (e.g., users of digital design objects in the research) is found in the records of museums' digital objects. Figure 1 shows the record of a digital design object (Flappy Bird, a mobile game, museum number: CD.27-2014) at the V\&A collection. The record that the metadata captures only describes where this application was made (Place of origin: Hanoi (capital of Vietnam), by whom it was made (Artist/Maker: Nguyen, Dong (programmer), GEARS Studios (games developers)), when it was made (Date released: 22/01/2014) and what it is made of (Materials and Techniques: Plastic, Metal, Glass, Android software (.APK) designed to run on a mobile phone)). This record demonstrates the conventions of museum documentation practice, which exclusively highlight the objects' provenance. Information about the perspectives of mobile game users (e.g., players), for instance, and sociotechnical systems wherein the game was operated were not documented since there is no metadata that speaks to these concepts. A lack of metadata to (re)present the agency of users of such objects causes the fragments of knowledge around the objects to be preserved.

Moreover, the record about the object's dimensions (Length: $129.9 \mathrm{~mm}$, Width: $65.9 \mathrm{~mm}$, Height: $11.6 \mathrm{~mm}$ ) is certainly not about the mobile application but the mobile phone on which the application ran. Furthermore, although its physical description is documented as a digital file, the mobile game application may be considered more than just a digital file, as a PDF 
file can also be called a digital file. I do not intend to criticize the quality of the object records; rather, I intend to underscore how the CMS and metadata in use are not appropriate means by which to document digital design objects like mobile applications at the museum. There is no vocabulary, no metadata, no framework that can represent such an object's materiality.

Moreover, the records' metadata only reflect the physicality of objects. Presumably, this is because it has been believed that the significance of objects is located and inscribed inside of them, encoded by their makers with clear intentions. Consequently, a singular narrative presented by such metadata only represents the makers' perspectives or the curators' perspectives on what the maker intended. Here, we can see the metadata empowered by museums, in return, is empowering museums and makers. This is a scenario wherein we come to realize the agency of data.

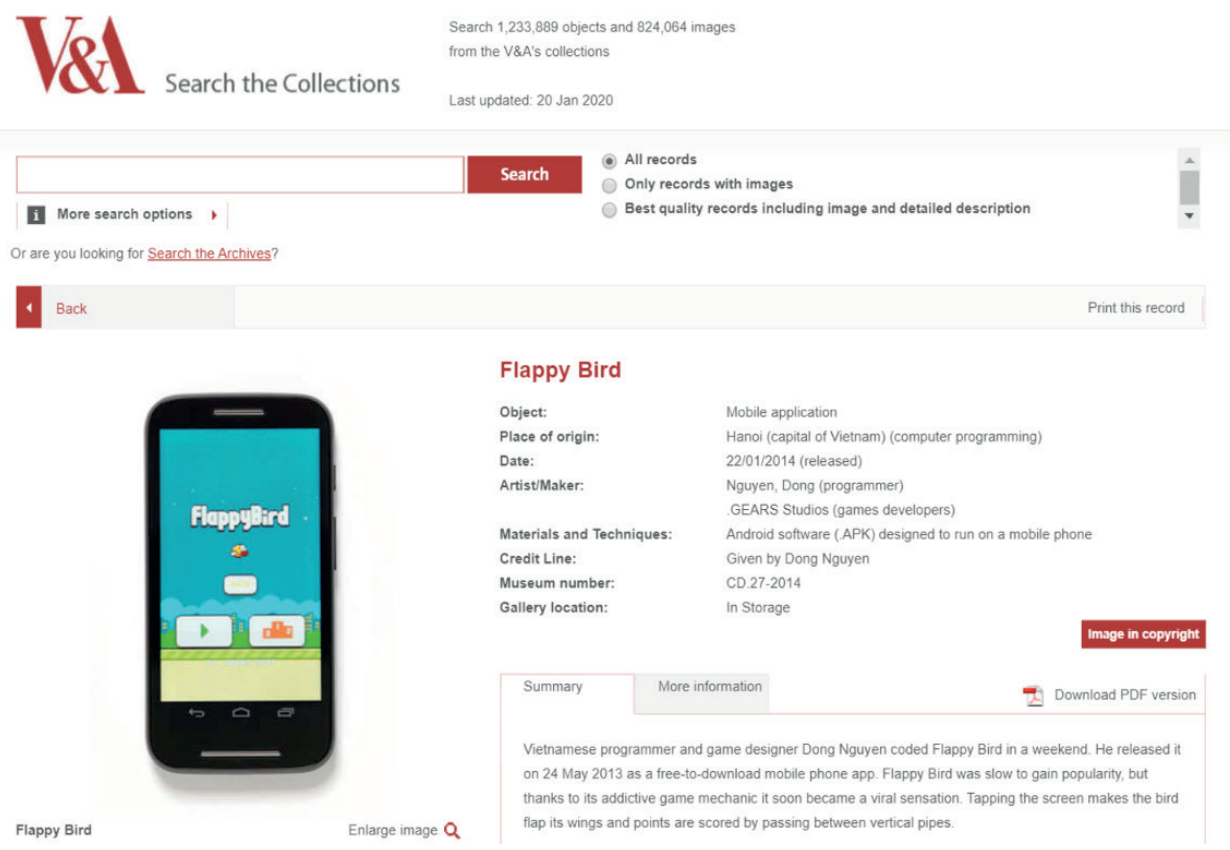

Figure 1 A screenshot of Flappy Bird records at the V\&A collection online

This active perspective about data (which I argue is the agency of data) is highlighted by Drucker (2011), who further suggests using the term 'capta' for information gained rather than given. Manovich also notes that data are not passive

Because data do not just exist - they have to be generated. Data creators have to collect data and organize it, or create it from scratch. Text needs to be written, photographs need to be taken, video and audio need to be recorded - or they need to be digitized from already-existing media (Manovich 2007: 43).

In other words, data are not just simply generated. Mechanisms and systems exist to define what data are and how they are interpreted. Metadata and records of museum collections are the result of the relational effects of networked actors. Certain data is created based on data standards and conventional procedures of museums (such as documentation protocols) or are privileged based on curatorial disciplines that museums use, such as art, history, or science (Cameron 2008). This is not a neutral process.

In the process of collecting Flappy Bird, the V\&A acquired archival materials such as a recording of the game in progress and material representing the viral output (YouTube videos and printed tweets) with an expectation that ' $[T]$ hese examples of the global response 
to the game may one day come to represent its original incarnation in the collection'. ${ }^{14}$ As Scholze (2016) argues, archival approaches are recommended when collecting designs to reflect the intangible, conceptual aspects of design. Those archival materials capture the interaction between the digital object, its users, and the technological system, wherein the digital object alone cannot be illustrated and materialized. This is because the materiality of digital objects, which are mass-produced and used by the general public, is arguably posed (Leonardi 2010) and performed (Drucker 2013) from, and valued by, not only their makers but also their users, the public. Such archival materials provide the potential to acknowledge the mobile application's real users (e.g., the actors who have directly experienced the materiality of and the agency of the digital object) and trace that agency which has been missing in the object's records and its metadata.

Ensmenger (2004: 95) emphasizes that '[T]he future of the history of computing is not machines, but people'. Current museums' collecting conventions and their documentation systems prioritize the physical, tangible dimensions of objects. The new type of collections, e.g., digital design objects, open up discussion on the significance of intangible, social dimensions of objects that can represent the agency of the general public - the users of such objects. Drawing on this discussion, the next section further argues for the need to adopt open, participatory models that acknowledge and invite the general public, as actors in the collections documentation process, to capture multiple voices around digital objects and visualize their materiality.

\section{The Museum's Online Catalogue: A Potential Space to Connect with New Actors}

The V\&A launched its first website in 1995 and its online catalogue, Search the Collections (StC), in $2009 . .^{15} \mathrm{StC}$ is a front-end online CMS. The CMS is hidden from online users, yet it is one of the core actors shaping what online visitors can read from StC. In the UK context, opening up the records of objects with images of them to the wider public has been 'part of the agreement that all government-funded museums have undertaken as part of their budget contract with the Department of Culture, Media and Sport (DCMS)' (Stevenson 2006: 91). The CMS, which was created for the museum's internal use only, is now connected to new actors (e.g., the public, internet technology, online interfaces, etc.) as a form of online catalogue. This section will present a critical analysis of the current online catalogue interface that constructs textual based-searching activity, then argue the need to reconsider an online catalogue as an open space where missing actors of CMSs and museums' digital design objects (e.g., the general public) can be invited to participate in the process of collections documentation.

Online catalogues' search systems of museums, including the V\&A, mostly rely on a textual search through metadata and words. Despite such search activity on online catalogues seemingly being taken for granted, it is all relational effects. As Drucker argues, 'The interface is not an object. Interface is a space of affordances and possibilities structured into organization for use. An interface is a set of conditions, structured relations that allow certain behaviours, actions, readings, events to occur' (Drucker 2013: para 31). In other words, from the point of view of ANT, actors connected with online catalogues' interfaces bind together to work in a way they intend. The metadata of CMSs, who acts as a spokesperson, connects museum objects, their records, and remote users online via online catalogues' interfaces. The mobility of metadata makes its agency even stronger as it now comes out of museums' internal systems and gets extended through the internet to wherever remote users access the catalogue online. It flows in the internet space, being on the move with a possibility to attract new actors and enlarge its network.

However, it is doubtful whether the metadata of collection records has been successful in attracting new actors (e.g., the general public). This is because, as Haskiya maintains, ' $[\mathrm{T}]$ he typical metadata created during cataloguing, aiming primarily to make internal collections more efficient, is often not well-suited to support the curiosity-driven exploration of the flaneur', who is looking for inspiration. ${ }^{16}$ Moreover, the textual-based, single search box that users first encounter in online catalogues was designed considering content experts as its main users (Windhager et al. 2019). In other words, online catalogues which still exclusively have strong connections with content experts, CMSs, and metadata are less likely to recognize 
online audiences as actors. The designed experience of online users on museums' online catalogues is to consume content provided by the pre-networked hybrid actors. No way is offered for the users to present their agency on the online catalogues.

The evolution of internet technologies has brought about the potential for museums' online catalogues to be a fluid, open space that not only connects wider audiences but also invites them to contribute to knowledge production around museum objects. This comes through acknowledging the agency of online audiences. Cameron and Robinson (2007) suggest polysemic interpretive models of museum collections documentation that can be read with the literature on participatory approaches to documentation practices, for instance, 'post-documentation' (Parry 2007), a 'participatory catalogue' (Srinivasan et al. 2009), and 'metadata co-creation' (Alemu 2018). About two decades have passed since the concept of participatory documentation was introduced in the museum sector (for example, social tagging based on Web 2.0 technology for public participation in building narratives around museum objects). However, online catalogues rooted in CMSs are maintained solely to support an official, singular narrative around objects (Srinivasan et al. 2009)..$^{17}$ In fact, applying the conceptual recommendations on participatory documentations is not a matter of the applicable digital technology but of heterogenous actor-networks having denied agency to those who have not been acknowledged within their network. Museums' conventions, standardized protocols, and policies related to collections documentation are not ready for a change from closed documentation systems.

It is the new type of museum collections (e.g., digital design objects), which is a driving force for a change to open, fluid, participatory documentation models. As discussed above, such objects' materiality can only be revealed through interaction (Leonardi 2010) and performance in use (Drucker 2013). The objects in museum storage or on display are isolated from their real users and the original social contexts that they used to function in. The users physically exist outside of museum walls while they can be digitally connected to the actor-network of the objects via online catalogue systems.

We must reassess the roles of museums' online catalogues within the context of a digital age. Providing only collection records online overlooks the affordance of online catalogues and internet technologies. I argue that open, fluid models of online catalogues that can support a participatory documentation process with real (and non-) users of digital design objects (e.g., the public) is necessary so that we can reflect and reveal the social dimensions of the materiality of such objects and build multiple narratives around them. In terms of methods used to implement this vision, museums can learn from crowdsourcing approaches and the oral history initiatives that archives and library sectors have developed to collect stories over the last decades (see, for example, Ridge 2014). The integration of content from open-collaborative online encyclopaedias such as Wikipedia with museums' collection records can be another possible approach (see, for example, Stinson et al. 2018), although contextualizing records to fit within museum contexts and content moderation issues must be considered at the same time.

\section{Conclusion: Participatory Documentations as a Method of Balancing Between Actors}

Through an ANT perspective, I depunctualized the CMS used at the V\&A and critically investigated the agencies of metadata of object records in the CMS and the search interaction on the museum's online catalogue. I demonstrated how the network of non-human actors (e.g., CMS, metadata, and online catalogues) and a selected certain group of human actors (e.g., museum professionals) have formed museums' collections documentation conventions. As shown above, the closed model of CMS hinders the (re)presentation of the social dimension of the materiality of the museum's digital design objects within the system. Further, it fails to recognize users of such objects (e.g., the public) and reflect their plural perspectives in collection records. Despite the technological potential of museums' online catalogues to be an open space where the public can contribute to the documentation of collection records, the current system only reinforces the existing actor-network of CMSs. Missing actors (e.g., the public) still do not have their voices represented in official records of museum collections. I have argued for a participatory approach to museum documentation practices so that the multiple 
contexts of digital design objects in use can be evident to represent the social dimension of the materiality of such objects through multi-narratives from the public. Particularly at a juncture where there is a strong desire to change the definition of museums to further emphasize their social relevance, the acceptance of multiple narratives around museum objects is in demand.

I acknowledge the theoretical and methodological limitations of this paper, since an actor is, in fact, a network. Therefore, unfolding an actor is an endless process from an ANT point of view (Miettinen 1999). Despite this criticism on the ANT, this paper demonstrates how significant it is to acknowledge the complexity of actor-networks of CMSs when understanding museums' data practices in a digital age. I recommend three directions of future research with the acknowledgement of this paper's limitation. Firstly, a case study on how museum practitioners use their CMS in a museum, via an ethnographic approach, would provide an indepth nuanced context to understand the interplay between the system and the organization. Secondly, a study on a museum's CMS or online catalogue from a perspective of critical code studies (see Marino 2020) would improve our understanding of such sociotechnical objects by revealing the agencies of program languages used and technical protocols. Lastly, an experimental research study for an application of participatory documentation would help build a framework for such an alternative method and identify gaps between the theoretical suggestion and practical use.

Using collections data, which are structured and machine-readable, is the process through which advanced computing technologies such as Al are extending their agencies. In this data landscape, the power of the actors who can mobilize (e.g., metadata) intensifies. As human actors, what we, museum professionals, must do is acknowledge the agency of non-human actors (e.g., data and technology) alongside that of missing actors (e.g., the public) in the process of collections documentation and endeavour to reflect various actors' perspectives more in our collection data practices.

Received: 4 February 2020

Finally accepted: 1 June 2021

\section{Acknowledgements}

The author wishes to thank the research project Content/Data/Object leads, Marion Crick, Corinna Gardner, Natalie Kane, and Richard Palmer, for sharing their insight, thoughts, and fruitful discussions; the project's Community Research Fellow, Anouska Samms, for being a supportive research partner with a warm heart; and the team of the V\&A Research Institute including Joanna Norman, Marta Ajmar, and Claudia Heidebluth, for enormous support in various ways. The research project has been supported by the Andrew W. Mellon Foundation.

\section{Notes}

1 See also International Council of Museums (ICOM), 'International Guidelines for Museum Object Information: The CIDOC Information Categories', 1995. http://network.icom.museum/ fileadmin/user_upload/minisites/cidoc/DocStandards/guidelines1995.pdf, accessed 15 March 2021.

2 See also Elena Villaespesa and John Stack, 'Finding the Motivation Behind a Click: Definition and Implementation of a Website Audience Segmentation', Museums and the Web 2015. https://mw2015. museumsandtheweb.com/paper/finding-the-motivation-behinda-click-definition-and-implementation-of-a-website-audience-segmentation, accessed 15 March 2021.

3 For more information on the project, see the project webpage: https://www.vam.ac.uk/ research/projects/content-data-object, accessed 15 March 2021.

4 See also Juhee Park and Anouska Samms, 'The Materiality of the Immaterial: Collecting Digital Objects at the Victoria and Albert Museum', Museums and the Web 2019. https:// mw19.mwconf.org/paper/the-materiality-of-the-immaterial-collecting-digital-objects-atthe-victoria-and-albert-museum, accessed 15 March 2021. 
5 Park and Samms, 'The Materiality of the Immaterial'.

6 Leonardi's (2012) distinction about the definitions of materiality, socio-materiality and socio-technical systems is potentially useful, but this paper will continue to use 'materiality' and 'social dimension of it' from a broad definition of materiality, rather than distinguishing a difference between the three.

7 Collections Trust, 'MuseumIndex+', n.d. http://collectionstrust.org.uk/software/ museumindex, accessed 15 March 2021.

8 Collections Trust, 'Museumlndex+'.

9 Collections Trust, 'Spectrum', 2017. https://collectionstrust.org.uk/spectrum, accessed 15 March 2021.

10 Victoria \& Albert Museum (V\&A), 'Collections Information and Access Policy', 20193. https://www.vam.ac.uk/info/reports-strategic-plans-and-policies, accessed 15 March 2021.

11 Victoria \& Albert Museum (V\&A), 'Collections Development Policy', 2019 9. https://www. vam.ac.uk/info/reports-strategic-plans-and-policies, accessed 15 March 2021.

12 Victoria \& Albert Museum, 'Collections Development Policy', 9.

13 See Park and Samms, 'The Materiality of the Immaterial'.

14 Kristian Volsing, 'The Rise and Fall of Flappy Bird and the Collecting of the V\&A's First App', V\&ABlog 16 July 2014. https://www.vam.ac.uk/blog/news/the-rise-and-fall-of-flappybird-and-the-collecting-of-the-vas-first-app, accessed 15 March 2021.

15 The V\&A launched a new version of StC, 'Explore the Collection', in February 2021 while this paper was under review. I focused only on the previous version due to time constraints. The CMS in which the online catalogue is rooted has not changed.

16 David Haskiya, 'An Evaluation of Generous Interfaces', Europeano Pro, 11 March 2019. https://pro.europeana.eu/page/issue-11-generous-interfaces, accessed 15 March 2021.

17 See also Neal Stimler and Louise Rawlinson, L. 'Where Are the Edit and Upload Buttons? Dynamic Futures for Museum Collections Online', Museums and the Web 2019. https:// mw19.mwconf.org/paper/where-are-the-edit-and-upload-buttons-dynamic-futures-formuseum-collections-online, accessed 15 March 2021.

\section{References}

Akrich, M. (1992) 'The De-scription of Technological Objects', in Wiebe E. Bijker and John Law (eds) Shaping Technology/Building Society: Studies in Sociotechnical Change, 205-24, Cambridge, MA: MIT Press.

Alemu, G. (2018) 'Metadata Enrichment for Digital Heritage: Users as Co-Creators', International Information \& Library Review, 50 (2) 142-56.

Allen-Robertson, J. (2018) 'Critically Assessing Digital Documents: Materiality and the Interpretative Role of Software', Information, Communication \& Society, 21 (11) 1732-46.

Baca, M. (ed) (2008) Introduction to Metadata, Los Angeles: The Getty Research Institute. 
Bearman, D. (2008) 'Representing Museum Knowledge', in Paul F. Marty and Katherine Burton Jones (eds) Museum Informatics: People, Information, and Technology in Museums, 35-57, New York: Routledge.

Bruni, A. (2005) 'Shadowing Software and Clinical Records: on the Ethnography of Nonhumans and Heterogeneous Contexts', Organization, 12 (3) 357-78.

Callon, M. (1986) 'Some Elements of a Sociology of Translation: Domestication of the Scallops and the Fishermen of St Brieuc Bay', in John Law (ed) Power, Action and Belief: A New Sociology of Knowledge?, 196-233, London: Routledge and Kegan Paul.

(1991) 'Techno-economic Networks and Irreversibility', in John Law (ed) A Sociology of Monsters: Essays on Power, Technology and Domination, 132-61, London; New York: Routledge.

Cameron, F. (2008) 'Object-oriented Democracies: Conceptualizing Museum Collections in Networks', Museum Management and Curatorship, 23 (3) 229-43.

(2020) 'Theorising Heritage Collection Digitisations in Global Computational Infrastructures', in Hannah Lewi, Wally Smith, Dirk vom Lehn and Steven Cooke (eds) The Routledge International Handbook of New Digital Practices in Galleries, Libraries, Archives, Museums and Heritage Sites, 55-67, Abingdon; New York: Routledge.

Cameron, F. and Robinson, H. (2007) 'Digital Knowledgescapes: Cultural, Theoretical, Practical, and Usage Issues Facing Museum Collection Database in a Digital Epoch', in Fiona Cameron and Sarah Kenderdine (eds) Theorizing Digital Cultural Heritage: A Critical Discourse, 165-91, Cambridge, MA; London: MIT Press.

Doolin, B. and Lowe, A. (2002) 'To Reveal is to Critique: Actor-Network Theory and Critical Information Systems Research', Journal of Information Technology, 17 69-78.

Drucker, J. (2011) 'Humanities Approaches to Graphical Display', Digital Humanities Quarterly, 5 (1) http://www.digitalhumanities.org/dhq/vol/5/1/000091/000091.html.

(2013) 'Performative Materiality and Theoretical Approaches to Interface', Digital Humanities Quarterly, 7 (1) http://www.digitalhumanities.org/dhq/ vol/7/1/000143/000143.html.

Ensmenger, N. (2004) 'Power to the People: Toward a Social History of Computing', IEEE Annals of the History of Computing, 26 (1) 93-5.

Gibson, J. (1986) The Ecological Approach to Visual Perception, Hillsdale, NJ: Lawrence Earlbaum.

Haigh, T. (2009) 'How Data Got its Base: Information Storage Software in the 1950s and 1960s', IEEE Annals of the History of Computing, 31 (4) 6-25.

Hanseth, O., Aanestad, M. and Berg, M. (2004) 'Actor-Network Theory and Information Systems. What's so Special?', Information Technology \& People, 17 (2) 116-23.

Jones, K.B. (2008) 'The Transformation of the Digital Museum', in Paul F. Marty and Katherine Burton Jones (eds) Museum Informatics: People, Information, and Technology in Museums, 9-25, New York: Routledge. 
Kallinikos, J., Leonardi, P. and Nardi, B. (2012) 'The Challenge of Materiality: Origins, Scope, and Prospects', in Paul M. Leonardi, Bonnie A. Nardi and Jannis Kallinikos (eds) Materiality and Organizing: Social Interaction in a Technological World, 1-21, Oxford: Oxford University Press.

Kéfi, H. and Pallud, J. (2011) 'The Role of Technologies in Cultural Mediation in Museums: An Actor-Network Theory View Applied in France', Museum Management and Curatorship, 26 (3) 273-89.

Latour, B. (2004) 'Nonhumans', in Stephan Harrison, Steve Pile and Nigel Thrift (eds) Patterned Ground: Entanglements of Nature and Culture, 224-27, London: Reaktion Books.

(2005) Reassembling the Social: An Introduction to Actor-Network Theory, Oxford: Oxford University Press.

Law, J. (1992) 'Notes on the Theory of the Actor Network: Ordering, Strategy and Heterogeneity', Systems Practice, 5 (4) 379-93.

Leonardi, P. (2010) 'Digital Materiality? How Artifacts Without Matter, Matter', First Monday, 15 (6) https://firstmonday.org/article/view/3036/2567.

(2012) 'Materiality, Sociomateriality, and Socio-Technical Systems: What Do These Terms Mean? How Are They Different? Do We Need Them?', in Paul M. Leonardi, Bonnie A. Nardi and Jannis Kallinikos (eds) Materiality and Organizing: Social Interaction in a Technological World, 25-48, Oxford: Oxford University Press.

Manovich, L. (2007) 'Database as Symbolic Form', in Victoria Vesna (ed) Database Aesthetics: Art in the Age of Information Overflow, 39-60, Minneapolis: University of Minnesota Press.

(2013) Software Takes Command: Extending the Language of New Media, London: Bloomsbury.

Marino, M. (2020) Critical Code Studies, Cambridge, MA: The MIT Press.

Marty, P. (2008) 'Museum Websites and Museum Visitors: Digital Museum Resources and Their Use', Museum Management and Curatorship, 23 (1) 81-99.

Miettinen, R. (1999) 'The Riddle of Things: Activity Theory and Actor-Network Theory as Approaches to Studying Innovations', Mind, Culture, and Activity, 6 (3) 170-95.

Oldman, D., Doerr, M. and Gradmann, S. (2016) 'Zen and the Art of Linked Data: New Strategies for a Semantic Web of Humanist Knowledge', in Susan Schreibman, Ray Siemens and John Unsworth (eds) A New Companion to Digital Humanities, 25173, Chichester: Wiley Blackwell.

Park, J. (2019) 'A life of WeChat: Challenges When Documenting the Network of a Mobile Application at the V\&A Collection', Annual Conference of the International Council of Museum (ICOM)'s CIDOC (International Committee for Documentation), Kyoto, Japan.

Parry, R. (2007) Recoding the Museum: Digital Heritage and the Technologies of Change, London: Routledge.

Pentland, B.T. and Singh, H. (2012) 'Materiality: What Are the Consequences?', in Paul M. Leonardi, Bonnie A. Nardi and Jannis Kallinikos (eds) Materiality and Organizing: Social Interaction in a Technological World, 287-95, Oxford: Oxford University Press. 
Ridge, M. (ed) (2014) Crowdsourcing Our Cultural Heritage, Farnham: Ashgate Publishing Limited.

Sayes, E. (2014) 'Actor-Network Theory and Methodology: Just What Does It Mean to Say That Nonhumans Have Agency?', Social Studies of Science, 44 (1) 134-49.

Scholze, J. (2016) 'Ghosts and Dancers: Immaterials and the Museum', in Liz Farrelly and Joanna Weddell (eds) Design Objects and the Museum, 61-9, London: Bloomsbury Academic.

Skinner, J. (2014) 'Metadata in Archival and Cultural Heritage Settings: A Review of the Literature', Journal of Library Metadata, 14 (1) 52-68.

Srinivasan, R., Boast, R., Furner, J. and Becvar, K. (2009) 'Digital Museums and Diverse Cultural Knowledges: Moving Past the Traditional Catalog', Information Society, 25 (4) 265-78.

Star, S.L. (1992) 'The Trojan Door: Organizations, Work, and the "Open Black Box"', Systems Practice, 5 (4) 395-410.

Sterne, J. (2014) 'What Do We Want? "Materiality!"', in Tarleton Gillespie Pablo J. Boczkowski and Kirsten A. Foot (eds) Media Technologies: Essays on Communication, Materiality, and Society, 119-28, Cambridge, MA: MIT Press.

Stevenson, J. (2006) 'Digitisation Programmes in the V\&A', in Lindsay W. MacDonald (ed) Digital Heritage: Applying Digital Imaging to Cultural Heritage, 69-92, Oxford: Butterworth-Heinemann.

Stinson, A.D., Fauconnier, S. and Wyatt, L. (2018) 'Stepping Beyond Libraries: The Changing Orientation in Global GLAM-Wiki', JLIS.it, 9 (3) 16-34.

Turner, H. (2015) 'Decolonizing Ethnographic Documentation: A Critical History of the Early Museum Catalogs at the Smithsonian's National Museum of Natural History', Cataloging \& Classification Quarterly, 53 658-76.

(2017) 'Organizing Knowledge in Museums: A Review of Concepts and Concerns', Knowledge Organization, 44 (7) 472-84.

Waller, L. (2016) 'Curating Actor-Network Theory: Testing Object-oriented Sociology in the Science Museum', Museum \& Society, 14 (1) 193-206.

Walsham, G. (1997) 'Actor-Network Theory and IS Research: Current Status and Future Prospects', in Allen S. Lee, Jonathan Liebenau and Janice I. DeGross (eds) Information Systems and Qualitative Research, 466-80, Boston, MA: Springer.

Wentz, P. (1995) 'Museum Information Systems: The Case for Computerization', in Anne Fahy (ed) Collections Management, 198-210, London; New York: Routledge.

Wilson, R.J. (2011) 'Behind the Scenes of the Museum Website', Museum Management and Curatorship, 26 (4) 373-89.

Windhager, F., Federico, P., Schreder, G., Glinka, K., Dork, M., Miksch, S. and Mayr, E. (2019) 'Visualization of Cultural Heritage Collection Data: State of the Art and Future Challenges', IEEE Transactions on Visualization and Computer Graphics, 25 (6) 2311-30. 


\section{Author}

Dr Juhee Park

dr.park.juhee@gmail.com

URL: https://www.linkedin.com/in/jpark-digitalculture/

Victoria and Albert Museum

United Kingdom

\section{Bio Statement}

Dr Juhee Park is Data Research Fellow at the V\&A in London, working on the research project Content/Data/Object which addresses challenges of collecting, documenting, and preserving digital design objects in the museum. She frequently delivers guest lectures on the topics of digital museums at universities in the UK and South Korea. Previously, she was Curator at the Gyeonggi Children's Museum in Korea where she received a commendation from the local government. Her research interests include critical digital heritage, digital participatory methods, the ecology of museum practices in the Al age, and Asian museology. 